\title{
Profile-oriented algorithms teaching: a proposed methodology
}

\author{
Fernando Moreira \\ Departamento de Economia, Gestão e Informática \\ Universidade Portucalense \\ 4200 Porto, Portugal \\ fmoreira@upt.pt
}

\author{
Maria João Ferreira \\ Departamento de Economia, Gestão e Informática \\ Universidade Portucalense \\ 4200 Porto, Portugal
}

mjoao@upt.pt

\begin{abstract}
One of the first challenges faced by students who are starting a Computer Science degree is to acquire skills which allow them solving real life problems through the use of algorithms. Such skills require the development of the ability to abstract as well as to apply algorithms development techniques. As a result of the difficulty in obtaining these competences, there are high failure and dropout rates in courses of related to this field of study. In order to solve this problem, we propose a methodology based on VARK questionnaire to define the students' profile and, consequently, what are their appropriate educational materials and tools.
\end{abstract}

Keywords - algorithms; VARK questionnaire; methodology; instructional materials; didactic tools.

\section{INTRODUCTION}

The acquisition of the skills required for developing computer programs is one of the first challenges that students have to cope with, when starting a degree in Computer Science or related field of study. Therefore, the course units (CU) Algorithms and Programming, Introduction to Programming, Data Structures, Object Oriented Programming, among others, are absolutely necessary in the first and second years of any of these degrees. Within the listed CUs, Algorithms and Programming is the one that holds a higher level of difficulty, on the one hand, due to the need to develop the abstraction ability, which is unknown or little practiced by many of the students. Additionally, it is also important to understand the notion of algorithm; algorithms consist in the basis for training in computing courses, as previously mentioned. In other words, algorithms are the basis for the development of programs in any language. For this reason, it is highly difficult, if not impossible, for a student to perform well in the UCs that required the use of educational programming languages without a reasonable knowledge of algorithms development techniques [1].

As mentioned, the algoritmia is known as a difficult subject for students, and is considered by many authors as coresponsible for high failure and dropout rates in many IT courses [2], [3].

Barcelos [4] emphasizes in his study the high students failure and dropout rates in CU algorithms, based on a research conducted during the school years 2008 and 2009 (2nd half of 2008 and the 1st and 2nd half of 2009). In this study, it was possible to assess the students' failure percentages above $50 \%$ in all semesters.
In order to improve the results of students in $\mathrm{CU}$ related to algorithms, they need to interact with the learning environment through all sensory directions, i.e., speaking, listening, reading, writing, as well as to experience and think about their own knowledge when attending the course content [5].

Active learning theories make teachers and students to actively participate in their learning environment in order to explore, experiment, test and apply the knowledge acquired in the classroom to solve real-life problems, as the main goal of algorithms development [6].

The main aim of the current research is to develop a proposal for a teaching-learning algorithms methodology oriented student profile, using the VARK questionnaire, and the identification of the most appropriate tools and materials that should be used in class, also according to the profile of students.

The rest of the paper is organized as follows. In the next section, a background of the addressed subjects is presented. The state of the art is described in the section III. In sections IV and $\mathrm{V}$ it is presented the methodology and the respective validation proposal is made. Finally, in the last section, conclusions are discussed.

\section{BACKGROUND}

\section{A. Algorithms}

The definition of algorithm has been given by several authors ([7], [8], among others) throughout time. In [7] algorithm is defined as an "ordered sequence and unambiguous steps which lead to the solution of one problem" while [8] defines the algorithm as "a finite set of rules that provides a sequence of operations for solve a specific type of problem"and states that "the notion of algorithm is basic to all computer programming.". It is interesting noting that the presented definitions are summarized in the definition provided by Merriam-Webster dictionary (http://www.merriamwebster.com/dictionary/algorithm), in which algorithm is characterized as" a set of steps that are followed in order to solve a mathematical problem or to complete a computer process".

To solve a problem by building a computer program, while using the computer as a tool and following the "rules", it is necessary to perform an ordered set of steps. At the first - one of the most important stages - the problem to be solved must be identified. In the second stage, a set of steps should be used 
in order to build the solution for the problem before starting using the computer. After the problem definition, a detailed analysis of the problem should also be performed in order to obtain a set of smaller problems. Similarly, these problems should then be divided into smaller problems until each one of them can be treated as an indivisible task and whose solution can be seen in a global way, i.e., as the problem solution. Finally, for each problem, an algorithm should be constructed, and subsequently coded in a programming language $(\mathrm{C}, \mathrm{C}$ \#, Java, etc.).

There are several ways to represent the algorithms, either in writing or schematic forms, and to translate the problem resolution. The most common forms of algorithms' representation are: (i) Narrative description - a form written in Portuguese / English; (ii) Conventional flowchart; (iii) Chapin Diagram and (iv) Pseudocode. Altogether, these different forms enable students to build solutions for to a proposed problem.

\section{B. Learning Styles}

Throughout the past few years, several researches have been conducted, regarding the preference of students for the type of teaching / learning, since they have different ways of learning and have different self-abilities [9]. However, a student learning preference may also change throughout time, along with his maturation, and acquisition of different skills. All the various models developed to explain the different learning styles were here grouped into four general categories: a) personality models, b) information processing models, c) models of social interaction, d) models of instructional preferences [10]. The incompatibility between the preferred learning style and educational strategy used by each teacher leads to several consequences, as presented in [11]: (i) inattentive students; (ii) discouragement by the course; (iii) low grades; (iv) lack of interest; (v) hostilities and (vi) limited cooperation.

Analyzing, in particular the category d) - models of instructional preferences - the model which has gained more popularity, is the Visual, Aural, Read/write, and Kinesthetic questionnaire (VARK) [12]. VARK questionnaire (http://varklearn.com/the-vark-questionnaire) is simple and is designed to, on the one hand, help students meet their learning profile more effectively and, on the other, help teachers becoming more sensitive as regards the variety of learning strategies needed to reach all students [13]. However, this questionnaire cannot be used to draw conclusions about the strengths or weaknesses of an individual during the learning process [14]. The VARK questionnaire consists of sixteen multiple-choice questions with four items each, corresponding to the four modalities $\mathrm{V}$, $\mathrm{A}, \mathrm{R}$ and $\mathrm{K}$ [12]. This tool is useful for teachers who are seeking to develop additional teaching and learning strategies [15], which should be more appropriate to the student's profile.

A student who has a V-type profile prefers to learn using graphics, symbolic representations, or video materials, or through the auditory input such as teacher's explanations or presentations. Obtaining an A type profile often indicates that a student perceives the information better if it is is auditory and verbal. This type of students prefers discussions, explanations or lectures, i.e., a more traditional behavioral approach (expositive classes). The student belonging to the type $\mathrm{R}$ profile prefer to get the input and to produce output through reading and writing, which represents information in the form of text instead of sound or images. Students with this profile are more favorable for self-study [16], [17]. The kinesthetic (K) profile fancies more practical experience rather than other modes of perception. For K-type profile student it is worth highlighting the importance of real or simulated practice; students can achieve better learning outcomes from practical demonstrations of teaching topics. Nevertheless, it should be mentioned that no teacher or student is restricted to only a learning preference mode.

\section{STATE OF THE ART}

In this research it has not found any work about the use of VARK questionnaire for profiling, and further development of materials and neither the choice of tools for students attending UC algorithms. However, the number of research papers discussing the issue of teaching algorithms is very extensive and covers a lot of areas of intervention.

As indicated above, despite the lack of research in this topic, it is important to show its evolution. In [4], the author presents a very interesting classification of several computer systems for teaching algorithms (about 31 proposals). It depends on the educational strategy, and points to the use of more than one strategy in the same proposal. The classification of the strategies used in the various proposals is: (i) Animation - nine proposals; (ii) Animation and flowcharts - four proposals; (iii) Collaboration - six proposals; (iv) Table Test three proposals; (v) Plays - five proposals; (vi) Portugol with four proposals; (vii) Graphs - two proposals; (viii) System Intelligent Tutor - two proposals, and (ix) Teaching objects one proposal .

In addition to these proposals it is possible to find a predominance of models using algorithms visualization tools [18], [19], [20], [21], [22]. Among the proposals analyzed, in the literature review presented in [22], which took place from 2001 to 2013, and concerns the visualization tools algorithms for teaching data structures, are presented seventeen different proposals. It is worth noting that the submitted proposals did not considered or investigated the profiles of the students as well as their preferred learning styles, which is the differential issue pointed in the methodology proposed in the ongoing investigation.

\section{PROPOSED METHODOLOGY}

In general, we can state that teachers should consider the learning styles of students while designing and throughout the development of UCs. Despite the fact that it may not be highly essential for teachers to test and instruct students in all situations, testing them with the VARK instrument - simple and fast - can provide important information to create an effective learning environment. To be aware of learning styles and considering its impact on the learning environments are the first steps towards an essential understanding of the profile of the students when developing a UC to teach algorithms.

\section{A. The study hypotheses and research methodology}

Two study hypotheses were set in order to understand the proposed methodology: (1) Can students with a profile obtained by VARK questionnaire have a better performance 
when targeted materials are used?; (2) It is possible to develop materials for a group whose the profiles are heterogeneous or in a group whose students have a predominant profile according to the results obtained from questionnaire VARK?

The obtained results will be based on a research technique that makes use of pre and post-tests that measure the knowledge acquired by students in a learning activity. Such tests consist on the application of a set of questions that must be answered by students before and after a particular activity. In particular, the pre-test allows determining the level of knowledge of participants on an issue that will be approached before training. The post-test consists in applying a set of questions with the same level of difficulty, in order to assess the evolution of the acquired skills [23].

The comparison between the pre-test notes and the posttest, together with the profile obtained through the VARK questionnaire, it is possible to understand the benefits of the activity and what are the appropriate materials to enhance the increased knowledge of the students and, consequently, lead to a decrease in failure and dropout rates [2], [3]. Furthermore, it should also contribute to the identification of the gaps present in the teaching-learning process regarding students that hold no predominant profile.

\section{B. Methodology}

As discussed previously it is important to define the students profile in order to help in the design and development of teaching materials. With this assumption a methodology is proposed. It consists of five different components with a defined sequence (Figure 1).

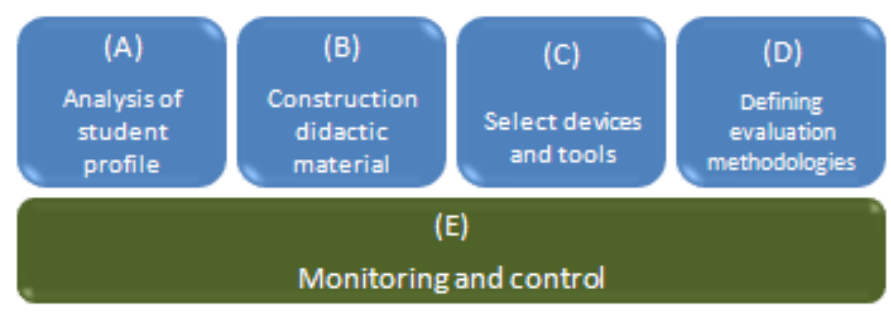

Figure 1. Methodology components.

In the component (A) the VARK questionnaire is used to analyze the profile of each one of the students who attend UC algorithms in order to understand what kind of teaching materials need to be built and made available for (B) (for instance, if those materials should be more descriptive or visual, etc). Based on the results and constructed materials it is necessary to carry out its distribution to different types of devices, namely, if the model is applied to classroom teaching, distance learning (e-learning), blended learning (b-learning), or to be used only in mobile devices (mobile learning, m-learning) (C). For instance, the use of e-learning or m-learning involves the production of materials appropriate for such type of devices. Some of the most important components in the teaching-learning models are the used evaluation methodologies (D). The whole methodology has a monitoring and control process (E) which allows the adjustment of the materials, devices used and evaluation methodology, as long as students and teachers understand these needs.

\section{Teaching materials}

As mentioned in previous sections, the use of different learning materials is required. For this reason, examples of teaching materials that meet the needs of each profile will be presented.

For students who have an A type profile, podcasts are a good approach. A podcast is a lesson / lecture prerecorded and distributed via Internet or in a mobile device, allowing students to hear it as often and when and where they want. There are many ways to share the podcast. Probably one of the most well-known is through iTunes. However, there are other tools, such as Audioboo (https://audioboom.com/about/education). An interesting example of using podcasts to support computer science education is podcasts produced by Alan O'Donohoe (http://audioboom.com/users/104685/boos).

For students with $\mathrm{V}$ type profile, tutorial videos and graphics are more appealing. Through the use of video tutorials, also known as vodcasting, the teacher can record the lesson / session and make it available in the Internet if shared share openly at YouTube, SchoolTube, TeacherTube, or more restrictively in the institution LMS platform. The class "Algorithms, Structures, Pseudocode, Flowcharts" (https://www.youtube.com/watch?v=eXH5Pg-VZks) is an example of the shared distribution of high quality content. In this context students can follow the lesson / session outside the classroom and use class time / session to explore the some other concepts in more detail.

For students with $\mathrm{R}$ type profile, wikis can be a good solution as it allows groups of individuals (students and teachers) to develop collaboratively sites without any knowledge or site design experience. Thus, a wiki can be used to save instructional videos and associated resources so that it is possible to assist in the concepts incorporation of algorithms abstraction. Students can then update the wiki and summarize what they have learned. Free tools like PBworks (http://pbworks.com/education) and Wikispaces Classroom (http://www.wikispaces.com) are hypotheses for creating wikis. Wikispaces Classroom extends the collaborative editing features of a wiki, including some additional features to support the lessons, characteristics such as social interaction and formative assessment. Teachers can also monitor how often the student reads, edits or save a page.

In the learning process of students with a K-type profile, each student learns by active physical activities, which is just the opposite of being passively listening to theoretical explanations, for example, through lectures and colloquia. This way, the elements introduced to meet this concept in teaching algorithms are the tools where the student can see the result of their algorithmic solution. These tools can include VisuAlg (http://www.guanabara.info/logica/Ferramentas/visualgv25.exe), the Webportugol

(http://www.guiadoexcel.com.br/webportugol/webportugol.html), among others. In this type of tools the student can observe the solution step by step and see how this is evolving, especially as a result of the feedback provided by the tools. This type of solution

${ }^{1}$ This link contains Java, and it obliges the user to "open" his/her computer to the Java security issues. 
contrasts with the traditional teaching algorithms solutions that are made by pencil and paper.

\section{Proposal for methodology validation}

In order to decide what is taught in the first lectures of algorithms, the VARK questionnaire must be completed by student, so it is possible to obtain the their profiles, as well as pre- and post-tests, so their knowledge can be assessed.

The lessons that take place between the pre and post-test should consist in carrying out teaching activities using the materials and tools according to the profile designed by the VARK questionnaire. In each lesson, students will receive a set of programming exercises (algorithms with different degrees of difficulty, but related to the same topic, for example, conditional structures). In the first lesson sequence programming will be addressed while the second it should be discussed the use of conditional structures. In the following lessons students will explore the supporting resources, according to their profile, or other profiles, for a better understanding of the concepts. Any assessment made by students will be used to understand the development of exercises on sequential programming and on the implementation of conditional structures. The exercise evaluation will be divided as follows: (i) Variables identification; (ii) Input; (iii) Processing; (iv) Results and (v) Conditional structures utilization.

The results will correlate the students' performance in the pre and post-test according to their profiles in order to verify the two hypotheses previously defined. This comparison should reflect the benefits of using training materials in accordance with the defined profile.

\section{CONCLUSIONS}

The ability to abstract and to perceive what an algorithm is can be the very first challenges to a student, which is starting his degree in a computer field of study. These two difficulties have been shown to induce the high failure and dropout rates of students in courses in this area.

This way, the main goal of the current research was the proposal of a methodology based on VARK questionnaire to define the students' profile and, consequently, what are the materials and tools more appropriate when teaching algorithms.

It was intended, in this research, to test the proposed methodology, and allow further development, based on the results obtained, in order to evaluate situations where a profile is predominant in a group of students. One possible solution, according to the size of the student group, is to build different student subgroups according to their profile.

\section{REFERENCES}

[1] R Sedgewick., K. Wayne, "Algorithms". Pearson Education. Boston, MA. USA. 2011.

[2] A. M Engelbrecht, P. J. Dilermando, G. S Nakamiti, F. Bianchi, "Algoritmos e Programação de Computadores.", Editora Campus, São Paulo, 2012.

[3] A. Gomes, J. Henriques, A. Mendes, "Uma proposta para ajudar alunos com dificuldades na aprendizagem inicial de programação de computadores" Educação, Formação e Tecnologia, 1, 2008, pp. 93-103.
[4] R. J. S Barcelos, "O Processo de Construção do Conhecimento de Algoritmos com o Uso de Dispositivos Móveis Considerando Estilos Preferenciais de Aprendizagem.", Tese de Doutorado. UFRGS. 2012

[5] C. Meyers, T. B. Jones, "Promoting Active Learning: Strategies for the College Classroom”, Jossey-Bass, 1993.

[6] W. Longmire, “A Primer on Learning Objects”. IN Circuits, A. L. (Ed.), ASTD Learning Circuits. 2000.

[7] J. P. Tremblay, R. Bunt, "Ciência dos computadores - Uma abordagem Algorítmica”. McGraw-Hill, 1983.

[8] D. E. Knuth, et al. "Selected Papers on Computer Languages", Stanford, CA, CSLI, 2003. Available at http://www.bitsavers.org/pdf/stanford/cs_techReports/STAN-CS-76562_EarlyDevelPgmgLang_Aug76.pdf.

[9] A. A. Kumar, A. Smriti, S. A. Pratap, G. Krishnee, "An analysis of gender differences in learning style preferences among medical students". Indian Journal of Forensic Medicine and Pathology, 5 (1), 2012pp. 9-16.

[10] S. C. Claxton, P. H. Murrell, "Learning styles: implications for improving education practices.", ASHE-ERIC higher education report 4. Washington, DC: Association for the Study of Higher Education, 1987.

[11] V. Lindermann, M. R Tarouco, M. Bercht,. "Estilos de Aprendizagem: um estudo de casos em turmas de algoritmos e programação" XIX Simpósio Brasileiro Informática e Educação - Fortaleza - CE, 2008.

[12] E. Bernardes, M. Hanna, "How do management students prefer to learn? Why should we care?" International Journal for the Scholarship of Teaching and Learning , 3 (1), 2009, pp. 1-12.

[13] MERLOT (Multimedia Educational Resource for Learning and Online Teaching): the active learning site with VARK learning styles inventory. Available www.merlot.org/merlot/viewCompositeReview.htm?id=145206

[14] R. Bednarik and P. Fr"anti. "Survival of students with different learning preferences." The 4th Annual Finnish / Baltic Sea Conference on Computer Science Education, Kolin Kolistelut/Koli Calling, 2004, pp. 121-125.

[15] M. Ramayah, P. Sivanandan, N. H. Nasrijal,. "Preferred learning style: Gender influence on preferred learning style among business students." Journal of US-China Public Administration, 6 (4), 2009, pp. 6578.

[16] N.D Fleming, "I'm different; not dumb. Modes of presentation (VARK) in the tertiary classroom", in Zelmer,A., (ed.) Research and Development in Higher Education, Proceedings of the Annual Conference of the Higher Education and Research Development Society of Australasia (HERDSA), Volume 18, 1995, pp. 308-313. Available at http://www.itu.dk/people/metteott/ITU_stud/Speciale/L\%E6ring/learnin gStyles/different_not_dumb.pdf.

[17] N. D Fleming, "Teaching and Learning Styles: VARK Strategies", Honolulu Community College, 2001. Available at http://www.varklearn.com/english/index.asp

[18] C. G. Foutsitzis, S. N. Demetriadis, "Teaching Algorithms with the Use of a Web-based Scripted Collaboration Environment and Algorithm Visualization Tool", International Conference on Intelligent Networking and Collaborative Systems, IEEE Computer Society, 2010, pp. 116-123, DOI 10.1109/INCOS.2010.38

[19] F. Alhosban, L. Burd, "Aural instruction with visualization in ELearning" Frontiers in Education Conference (FIE), IEEE Seattle, WA, 2012, pp. 1 - 6, DOI: 10.1109/FIE.2012.6462290

[20] G. Törley, "Algorithm Visualization in Teaching Practice", Acta Didactica Napocensia 7 (1), pp. 1-17, 2014

[21] R. Libeskind-Hadas, "A Derivation-First Approach to Teaching Algorithms", SIGCSE'13, ACM, Denver, Colorado, USA, 2013, pp. 573-578,

[22] U. Pathania, A. Singh, "Visualization Tools of Data Structures Algorithms - A Survey", International Journal of Advanced Research in Computer Science and Software Engineering 4(3), March, 2014, pp. 338-341

[23] I-TECH, "Technical Implementation Guide. Guidelines for Pre- and Post-Testing". University of Washington. Seattle, Washington. USA. 2008 . 